\title{
Interaction of Opioids and Vasopressin in Central Action of Angiotensin II in Conscious Rabbits
}

\author{
Masayo Fukuhara, Kiyoshi Matsumura, Isao Abe, and Masatoshi Fujishima
}

\begin{abstract}
It has been demonstrated that opioids modulate the renin-angiotensin and sympathetic nervous systems. To clarify the interaction of central angiotensin II (Ang II) and endogenous opioids, we studied the effects of naloxone, an opioid antagonist, on cardiovascular and sympathetic responses to intracerebroventricular (ICV) Ang II in conscious rabbits. ICV Ang II (20 ng/min) significantly increased mean arterial pressure (MAP), plasma epinephrine, and arginine vasopressin (AVP) levels, with no significant change in renal sympathetic nerve activity (RSNA) or heart rate. Pretreatment with intravenous naloxone $(0.1 \mathrm{mg} / \mathrm{kg})$ failed to alter the cardiovascular and neurohormonal responses to ICV Ang II. To eliminate the effect of AVP on cardiovascular and sympathetic responses, $\left[\mathrm{d}\left(\mathrm{CH}_{2}\right)_{5} \mathrm{Thy}(\mathrm{Me})\right] \mathrm{AVP}$, a vasopressin $V_{1}$-receptor antagonist, was given intravenously. Pretreatment with intravenous injection of the $\mathrm{V}_{1}$-receptor antagonist $(30 \mu \mathrm{g} / \mathrm{kg})$ augmented the maximum increase in RSNA caused by ICV Ang II $(8.9 \pm 2.2$ vs. $16.2 \pm 0.7 \%, p<0.05)$. Combined pretreatment with naloxone and $V_{1}$-receptor antagonist further increased MAP and RSNA in response to ICV Ang II $(20 \pm 1$ vs. $16 \pm 2 \mathrm{mmHg}, p<0.05$, and $30.9 \pm 3.7$ vs. $16.2 \pm 0.7 \%, p<0.01$, respectively). These results suggest that opioids and AVP synergistically modulate sympathetic outflow so as to suppress the central pressor action of Ang II in conscious rabbits. (Hypertens Res 1998; 21: 89-95)
\end{abstract}

Key Words: catecholamines, central nervous system, naloxone, sympathetic nervous system, $V_{1}$-receptor antagonist

Various lines of evidence suggest that angiotensin II (Ang II) participates in cardiovascular regulation not only by its direct effect on vascular smooth muscle but also via its action on the central nervous system $(1,2)$. Central administration of Ang II increases blood pressure, plasma catecholamines, and arginine vasopressin (AVP) levels (1-3). However, the role of sympathetic nerve activity in this response has been somewhat controversial $(2,4,5)$. Although several investigators have demonstrated excitation of sympathetic nerve activity with Ang II $(3,4)$, others $(5)$ failed to show any stimulative effects. The divergent responses of sympathetic outflow seem to depend upon the species or the state of consciousness of animals used in the experiment. In addition, central administration of Ang II causes the secretion of AVP, which may modulate the cardiovascular and sympathetic responses to central Ang II (3). However, the role of AVP on cardiovascular and sympathetic responses to central Ang II has not been fully elucidated.

Endogenous opioids, such as $\beta$-endorphin, have also been located in sites involved in central cardiovascular control, such as the hypothalamus and the nucleus tractus solitarius, where baroreceptor and chemoreceptor afferents terminate $(6,7)$. Hypertension has been shown to be associated with elevated levels of endogenous opioids, and the opioid antagonist naloxone attenuates the development of hypertension in spontaneously hypertensive rats $(8)$ and two-kidney one-clip Goldblatt rats (9). It has been shown that naloxone abolishes the centrally, but not peripherally, mediated pressor action of Ang II, and the addition of morphine facilitates the central vasomotor action of Ang II (10). Furthermore, AVP release induced by acute hemorrhage is inhibited by endogenous opioids (11). In previous studies, we have clarified the central effects of opioids on the sympathetic nervous system and baroreceptor reflex $(12,13)$. We hypothesized that cardiovascular and sympathetic responses to central Ang II may be modulated by AVP or opioid peptides. Thus, the present study was designed to determine 1) the central effects of Ang II on the sympathetic nervous system, including the direct recordings of renal sympathetic nerve activity (RSNA), and 2) the role of interactions between opioids and AVP in the central effects of Ang II in conscious rabbits.

\section{Methods}

Preparation of Animals

The experiments were conducted on male Japanese

From the Second Department of Internal Medicine, Faculty of Medicine, Kyushu University, Fukuoka, Japan.

Address for Reprints: Kiyoshi Matsumura, M.D., Second Department of Internal Medicine, Faculty of Medicine, Kyushu University, Maidashi 3-1-1, Higashi-ku, Fukuoka 812-8582, Japan.

Received November 19, 1997; accepted in revised form February 24, 1998. 
White rabbits weighing 2.5 to $3.0 \mathrm{~kg}$. All experiments were carried out according to the institutional guidelines for animal experimentation at Kyushu University. Rabbits were anesthetized with pentobarbital sodium $(30 \mathrm{mg} / \mathrm{kg}$ iv). Three days before experimentation, electrodes were implanted in the left renal sympathetic nerve, and a stainless steel cannula was placed in the right lateral cerebral ventricle. RSNA was recorded as described previously $(12-14)$. Briefly, under aseptic conditions, the left kidney was exposed retroperitoneally, and a branch of the renal nerve was separated from the renal plexus and the surrounding connective tissues with the use of a dissecting microscope. RSNA was recorded by a pair of electrodes made from Teflon-insulated seven stranded steel wire (Medwire, Mt Vernon, NY). The area of the nerve and wire interface was embedded in silicone cement (Silgel 604A and B cement, Wacker Chemicals East Asia, Tokyo, Japan).

A 23-gauge stainless steel cannula was implanted into the right lateral cerebral ventricle $(4 \mathrm{~mm}$ lateral to the bregma and $6 \mathrm{~mm}$ below the cerebral surface). The position of the cannula in the lateral cerebral ventricle was confirmed after the injection of $0.1 \mathrm{ml}$ dye at the end of the experiments. The cannula was fixed to the skull with three jeweler's screws and dental cement. A 27-gauge obturator was used to seal the cannula. After surgery, disodium sulbenicillin (200 $\mathrm{mg}$ iv) was given to the rabbits to prevent postoperative infection.

Three and six days after the surgical procedures, the following experiments were carried out on a conscious rabbit placed in a holding box. On the experimental day, polyethylene catheters (PE-50) were inserted into the central ear artery and marginal ear vein under $1 \%$ lidocaine local anesthesia. The arterial catheter was connected to a pressure transducer (P50, Gould Statham Instruments, Hato Rey, Puerto Rico) to measure arterial pressure. Heart rate (HR) was monitored by a cardiotachometer (model 1332, NEC San-ei, Tokyo, Japan).

\section{Dose-Response Relationship of ICV Ang II and Arterial Pressure \\ At least 3 days after the surgical procedure, the dose-response relationship of ICV Ang II and the increase in arterial pressure was determined in con- scious rabbits $(n=6)$. Five doses of Ang II $(2.5,5$, $10,20,40 \mathrm{ng} / \mathrm{min})$ were infused with a compact syringe pump (Eicon EP60, Eicon Co., Kyoto, Japan) at a flow rate of $2 \mu \mathrm{l} / \mathrm{min}$ via the ICV cannu- la. The administration of each dose of Ang II was separated by a period of $30 \mathrm{~min}$.}

Effects of Naloxone on Cardiovascular and Neurohormonal Responses to ICV Ang II

Three and six days after the surgical procedure, the experiments were carried out using the same rabbits in a crossover design. On each experimental day, the rabbits $(n=6)$ were given an intravenous injection of vehicle $(0.9 \% \mathrm{NaCl})$ or $0.1 \mathrm{mg} / \mathrm{kg}$ naloxone (Sigma Chemical, St Louis, MO) in a volume of 0.5 $\mathrm{ml}$. Ten minutes later, a 2.4-ml sample of blood was withdrawn from the arterial catheter to measure plasma catecholamines (epinephrine and norepinephrine), plasma AVP, and hematocrit; Ang II $(20 \mathrm{ng} / \mathrm{min})$ was then infused with a compact syringe pump at flow rate of $2 \mu \mathrm{l} / \mathrm{min}$ via the ICV cannula. Additional blood samples were withdrawn 15, 30, and $60 \mathrm{~min}$ after beginning the ICV infusion of Ang II, and the withdrawn blood was replaced by the same volume of $0.9 \%$ saline. Arterial pressure, HR, and RSNA were monitored continuously during the entire experimental period. In our preliminary experiments, ICV infusion of $20 \mathrm{ng} / \mathrm{min}$ Ang II did not significantly increase plasma Ang II concentration in conscious rabbits. Plasma Ang II concentrations before and $60 \mathrm{~min}$ after ICV Ang II $(20 \mathrm{ng} / \mathrm{min})$ were $19.0 \pm 4.2$ and $13.7 \pm 1.5 \mathrm{pg} / \mathrm{ml}$, respectively $(n=3)$.

Combined Effects of Naloxone and Vasopressin $V_{1^{-}}$ Receptor Antagonist on Cardiovascular and Sympathetic Responses to ICV Ang II

Three and six days after the surgical procedure, the experiments were carried out using the same rabbits in a crossover design. On each experimental day, the rabbits $(n=6)$ were given an intravenous injection of vehicle $(0.9 \% \mathrm{NaCl})$ or $0.1 \mathrm{mg} / \mathrm{kg}$ naloxone in a volume of $0.5 \mathrm{ml}$. Five minutes after the injection of either vehicle or naloxone, the rabbits were given an intravenous injection of $\left[\mathrm{d}\left(\mathrm{CH}_{2}\right)_{5} \mathrm{Tyr}(\mathrm{Me})\right]$ vasopressin $(30 \mu \mathrm{g} / \mathrm{kg}$; Sigma Chemical, St Louis, $\mathrm{MO})$, a vasopressin $\mathrm{V}_{1}$-receptor antagonist, in a volume of $0.5 \mathrm{ml}$. Ten minutes after the injection of either naloxone or vehicle plus the $V_{1}$-receptor antagonist, Ang II (20 ng/min) was infused via the ICV cannula. Arterial pressure, HR, and RSNA were monitored continuously.

In the preliminary study, intravenous injection of $\mathrm{V}_{1}$-receptor antagonist $(30 \mu \mathrm{g} / \mathrm{kg})$ alone did not cause any changes in MAP, HR, or RSNA, but it prevented the pressor response to intravenous injection of AVP $(40 \mathrm{mU} / \mathrm{kg})$.

\section{Recording Procedures of RSNA}

RSNA was amplified (model DPA-100E, Dia Medical System, Tokyo, Japan) and filtered (100-3,000 $\mathrm{Hz}$ ), and the waveforms were integrated after fullwave rectification, using an integrator amplifier (model 1322, NEC San-ei) with the sample-hold function reset to baseline by an internal timer set at $5 \mathrm{~s}$. Absolute values for integrated RSNA were corrected before data analysis by subtracting the residual electrical output (noise level) recorded from the integrator after intravenous injection of phenylephrine $(32 \mu \mathrm{g} / \mathrm{kg})$.

\section{Blood Collection and Analysis}

EDTA-2Na was used as anticoagulant to obtain plasma. Blood samples for measurement of plasma catecholamines and plasma AVP were centrifuged at $4^{\circ} \mathrm{C}$. Plasma for catecholamines was stored at $-80^{\circ} \mathrm{C}$, and other plasma samples were stored at $-20^{\circ} \mathrm{C}$ until assay. Plasma catecholamine concentrations were measured by high-performance liquid chromatography (15-17), and plasma AVP levels were measured by radioimmunoassay (14). The 
assay sensitivities for AVP and catecholamines (epinephrine and norepinephrine) were $0.45 \mathrm{pg} / \mathrm{ml}$ and $10 \mathrm{pg} / \mathrm{ml}$, respectively.

\section{Statistics}

All values are expressed as means \pm SE. To determine the effects of ICV Ang II on hormonal responses, a one-way analysis of variance with repeated measurements was performed, followed by Duncan's multiple range test to determine which means differed from the control means. A paired $t$ test was used to determine the effects of naloxone on the responses of MAP, HR, and RSNA to central Ang II in animals pretreated with the intravenous $V_{1}$-receptor antagonist or vehicle. Student's $t$-test was applied to determine the effects of $\mathrm{V}_{1}$-receptor antagonist on the responses of MAP and RSNA induced by central Ang II after pretreatment with either intravenous naloxone or vehicle. A value of $p<0.05$ was considered to indicate statistical significance.

\section{Results}

Dose-Response Relationship of ICV Ang II and Arterial Pressure

Baseline values for MAP and HR before Ang II ICV injections were $83 \pm 2 \mathrm{mmHg}$ and $208 \pm 15$ beats/min, respectively. ICV Ang II elicited a dose-

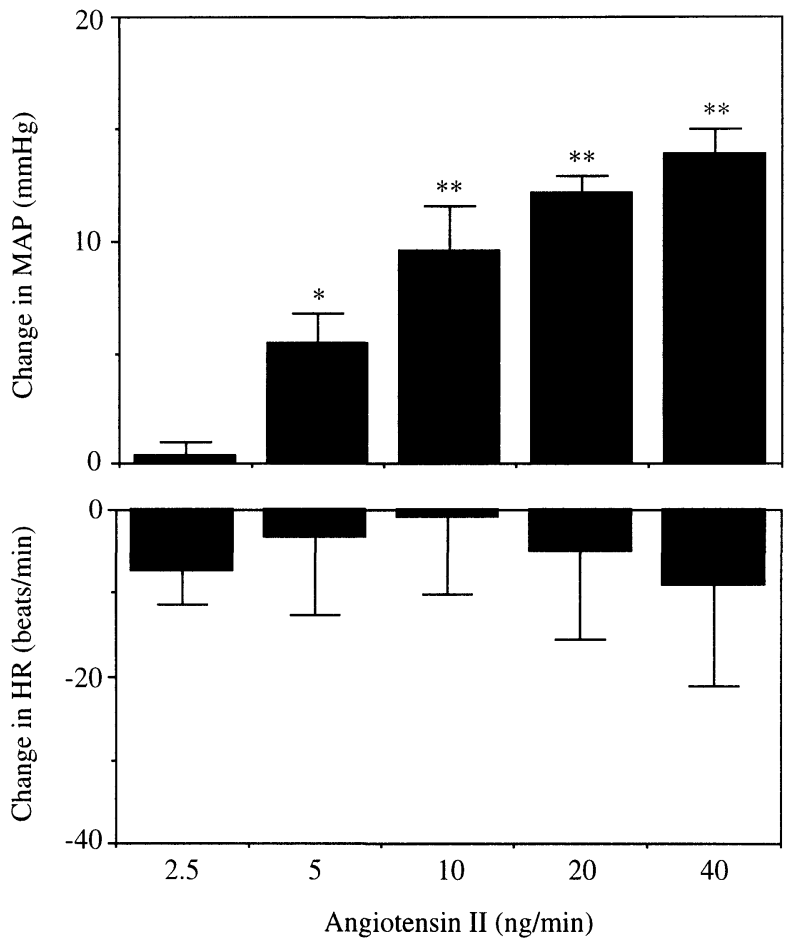

Fig. 1. Bar graphs showing central effect of five doses of Ang II (2.5, 5, 10, 20, $40 \mathrm{ng} / \mathrm{min})$ on changes in mean arterial pressure $(M A P)$ and heart rate $(H R)$ in 6 rabbits. Values are means $\pm S E .{ }^{*} \mathrm{p}<0.05,{ }^{* *} \mathrm{p}<0.01$ as compared with respective control by paired $\mathrm{t}$-test. related increase in MAP with no significant change in HR (Fig. 1). Twenty $\mathrm{ng} / \mathrm{min}$ of Ang II caused a sufficient increase in MAP $(12 \pm 1 \mathrm{mmHg})$; this dose of Ang II was used in the next experiment.

Effects of Naloxone on Cardiovascular and Neurohormonal Responses to ICV Ang II

Pretreatment with intravenous naloxone $(0.1 \mathrm{mg} / \mathrm{kg})$ had no effect on baseline MAP $(82 \pm 2 v s$. $81 \pm 4$ $\mathrm{mmHg}$, vehicle vs. naloxone) or $\mathrm{HR}(200 \pm 7 v s$. $198 \pm 17$ beats/min, vehicle $v s$. naloxone). ICV infusion of Ang II caused an increase in MAP, which was of similar magnitude in animals pretreated with vehicle or with naloxone (Fig. 2). In response to ICV Ang II, neither HR nor RSNA changed significantly, and the response was not changed by pretreatment with naloxone.

Table 1 illustrates the neurohormonal and hematocrit responses to ICV Ang II. In response to ICV Ang II, plasma epinephrine and AVP showed sus-
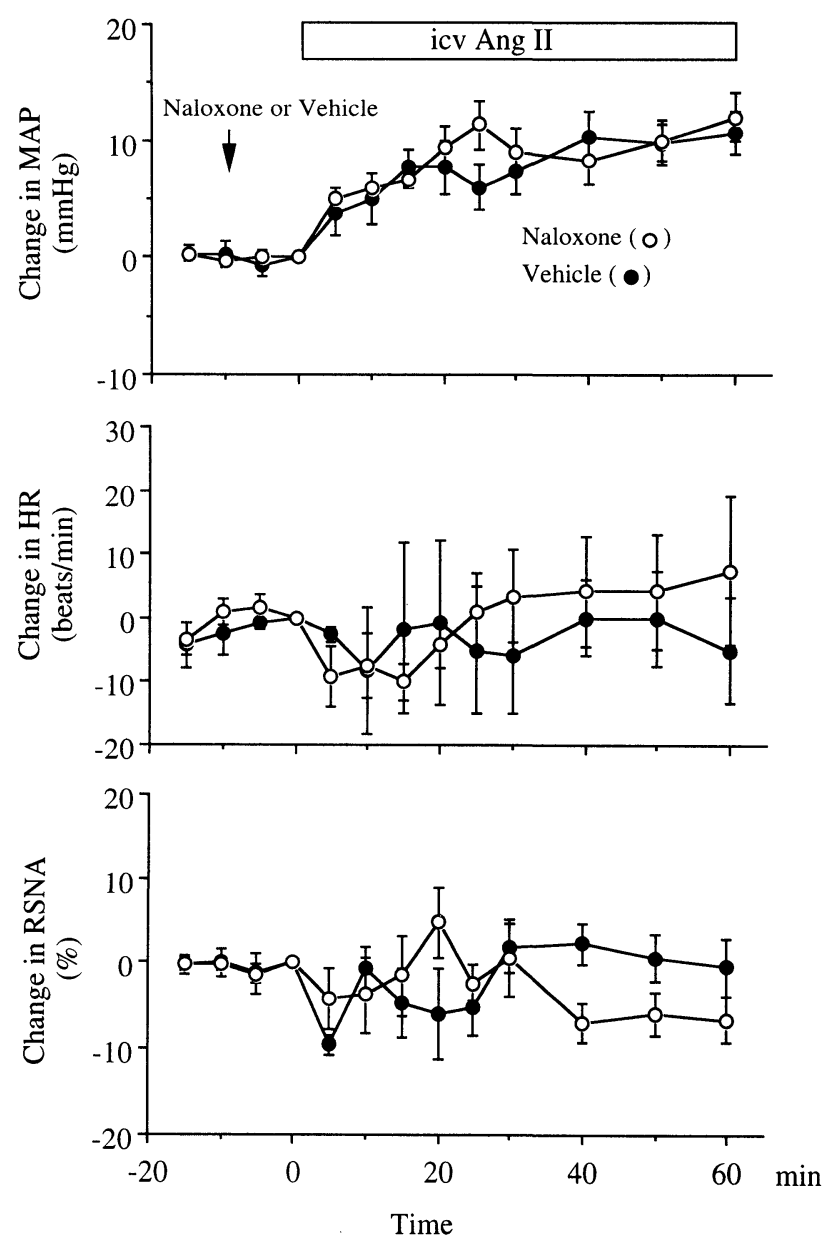

Fig. 2. The time course of changes in mean arterial pressure (MAP), heart rate (HR), and renal sympathetic nerve activity (RSNA) elicited by intracerebroventricular (icv) Ang II (20 ng/min) with (open circles) or without (solid circles) intravenous naloxone $(0.1 \mathrm{mg} / \mathrm{kg})$ pretreatment in 6 rabbits. Values are means $\pm S E$. 
Table 1. Effects of Naloxone on Neurohormonal Response to Intracerebroventricular Angiotensin II

\begin{tabular}{|c|c|c|c|c|}
\hline & \multicolumn{4}{|c|}{ Time $(\min )$} \\
\hline & 0 & 15 & 30 & 60 \\
\hline \multicolumn{5}{|c|}{ Epinephrine (pg/ml) } \\
\hline Vehicle & $10 \pm 0$ & $320 \pm 150 *$ & $180 \pm 30 *$ & $40 \pm 20$ \\
\hline Naloxone & $10 \pm 0$ & $210 \pm 60 *$ & $70 \pm 40$ & $180 \pm 70 *$ \\
\hline \multicolumn{5}{|c|}{ Norepinephrine $(\mathrm{pg} / \mathrm{ml})$} \\
\hline Vehicle & $170 \pm 20$ & $260 \pm 50$ & $260 \pm 30$ & $220 \pm 30$ \\
\hline Naloxone & $240 \pm 40$ & $260 \pm 50$ & $210 \pm 10$ & $270 \pm 10$ \\
\hline \multicolumn{5}{|l|}{$\operatorname{AVP}(\mathrm{pg} / \mathrm{ml})$} \\
\hline Vehicle & $2.4 \pm 0.6$ & $9.4 \pm 4.4 *$ & $5.9 \pm 0.4 *$ & $8.7 \pm 1.5^{*}$ \\
\hline Naloxone & $2.3 \pm 0.4$ & $5.9 \pm 1.3 *$ & $5.7 \pm 0.6^{*}$ & $6.7 \pm 0.8 *$ \\
\hline \multicolumn{5}{|c|}{ Hematocrit (\%) } \\
\hline Vehicle & $33.0 \pm 0.8$ & $33.6 \pm 0.9$ & $32.7 \pm 0.7$ & $33.0 \pm 0.6$ \\
\hline Naloxone & $33.0 \pm 0.6$ & $32.4 \pm 0.5$ & $31.7 \pm 0.3$ & $32.4 \pm 0.4$ \\
\hline
\end{tabular}

Values are means $\pm \mathrm{SE}(n=6)$. AVP; arginine vasopressin. ${ }^{*} p<0.05$ vs. control period by Duncan's multiple range test.

tained increases during the entire infusion period. In contrast, plasma norepinephrine did not change in response to ICV Ang II. Pretreatment with naloxone had no effect on Ang II-induced neurohormonal responses.

Combined Effects of Naloxone and Vasopressin $V_{1^{-}}$ Receptor Antagonist on Cardiovascular and Sympathetic Responses to ICV Ang II

Similar to the baseline values in Fig. 2, treatment of animals with naloxone had no effect on baseline MAP, HR, or RSNA (Fig. 3). The addition of $\mathrm{V}_{1-}$ receptor antagonist to naloxone and vehicle did not cause any changes in baseline MAP, HR, or RSNA. Blockade of AVP potentiated the increases in MAP and RSNA in naloxone-treated animals as compared with vehicle-treated animals. Figure 4 compares the maximum peak changes in MAP and RSNA in response to ICV Ang II and $V_{1}$-receptor antagonist in the absence and presence of naloxone. Naloxone alone had no effect on the peak changes in MAP and RSNA. In the absence of naloxone, blockade of AVP had no effect on the changes in MAP after central Ang II infusion, but significantly augmented the maximum increase in RSNA (16.2 \pm $0.7 v s .8 .9 \pm 2.2 \%, p<0.05$ by Student's $t$-test). Combination of the $\mathrm{V}_{1}$-receptor antagonist with intravenous naloxone further potentiated the peak pressor $(20 \pm 1 \mathrm{vs}$. $16 \pm 2 \mathrm{mmHg}$, with and without naloxone, $p<0.05)$ and renal sympathetic nerve $(30.9 \pm 3.7 v s$. $16.2 \pm 0.7 \%$, with and without naloxone, $p<0.01$ ) responses to ICV Ang II.

\section{Discussion}

The principal finding of the present study was that AVP interacted with opioid peptides to alter the centrally elicited cardiovascular and sympathetic responses to Ang II. Combined pretreatment with $\mathrm{V}_{1^{-}}$ receptor antagonist and naloxone augmented the responses of blood pressure and RSNA to ICV Ang II, suggesting a synergistic interaction between these two peptides in blunting central Ang II responses. In addition, blockade of AVP by $\mathrm{V}_{1}$-receptor antagonist alone selectively augmented the Ang II responses of RSNA, without a significant change in MAP. In contrast, blockade of opioids alone by naloxone had no effect on the Ang II responses. To our knowledge, this is the first study to demonstrate interactions among opioid peptides, AVP, and central Ang II in conscious animals.

Evidence has been presented that sympathetic stimulation, the release of AVP, and interference with the baroreceptor reflex can contribute to the central pressor action of Ang II (1-3). Unger et al. (3) demonstrated that peripheral blockade of $\alpha$ adrenoceptors or AVP partially inhibited the pressor responses to central Ang II in conscious rats. In the present study, however, AVP antagonist did not alter the responses of arterial pressure to central Ang II. The difference in the results between the present study and theirs may be due to the different species used in the experiments or the method of administration (bolus injection or infusion) of ICV Ang II. However, the primary contributor to the pressor response to ICV infusion of Ang II in the present study seems to be sympatho-adrenal activation, because the plasma catecholamine level increased and vasopressin $\mathrm{V}_{1}$-receptor antagonist failed to inhibit the pressor response to ICV Ang II.

Sympathetic outflow to central administration of Ang II has been controversial, depending on the details of experimental protocols, such as species, site of injection, state of consciousness, or the specific regional sympathetic nerve being recorded (2, 4 ), although few studies have recorded sympathetic nerve activity of conscious animals $(3,5)$. Our studies have the advantage of directly recording RSNA in conscious rabbits, and thereby avoiding the blunting of baroreceptor reflex and alteration of sympathetic outflow by anesthesia $(18,19)$. In the present study, ICV Ang II caused significant increases in MAP, plasma epinephrine, and AVP levels, with no significant changes in RSNA or HR. 

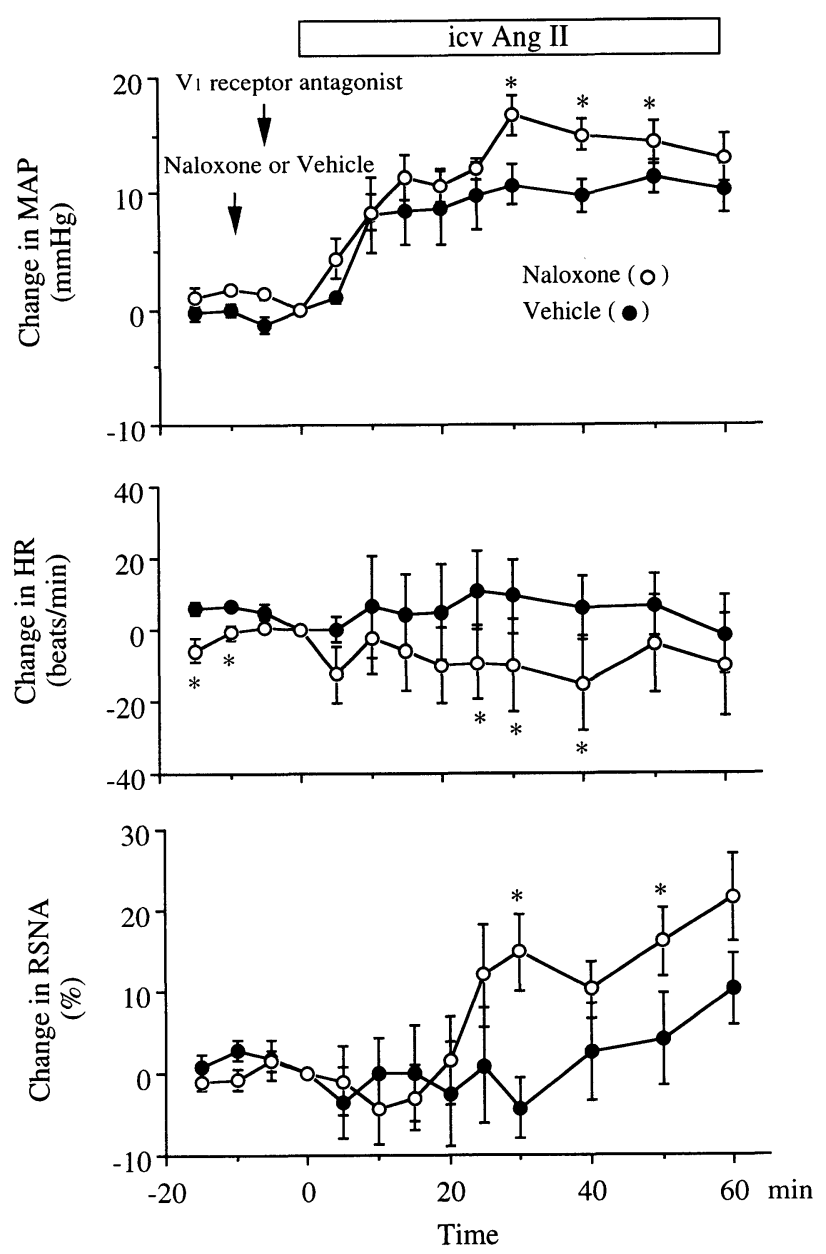

Fig. 3. Effect of vasopressin $V_{1}$-receptor blockade $(30$ $\mu \mathrm{g} / \mathrm{kg}$ iv) on the time course of changes in mean arterial pressure (MAP), heart rate (HR), and renal sympathetic nerve activity (RSNA) elicited by intracerebroventricular (icv) Ang II $(20 \mathrm{ng} / \mathrm{ml})$ with (open circles) or without (solid circles) intravenous naloxone $(0.1 \mathrm{mg} / \mathrm{kg})$ pretreatment in 6 rabbits. Values are means $\pm S E$. $* \mathrm{p}<0.05$ vs. pretreatment with vehicle by paired $\mathrm{t}$-test.

The pressor response to ICV Ang II was most likely attributable to the enhanced sympatho-adrenal outflow, since plasma epinephrine levels increased. However, RSNA did not change significantly during ICV infusion of Ang II. In our previous experiments in conscious rabbits, ICV injections of endothelin-1 (14), agonists of opioid peptides (13), and an inhibitor of nitric oxide synthase (20) caused significant increases in blood pressure with significant increases in RSNA and plasma catecholamine levels. In contrast, ICV Ang II increased blood pressure and plasma catecholamine levels, with no significant change in RSNA. Although all of these peptides elicit central pressor effects, the activation mechanisms of renal sympathetic outflow in response to ICV Ang II seem to differ from those of other neuropeptides.

The blunted response of RSNA to ICV Ang II in the present study is supported by Matsumura et al.
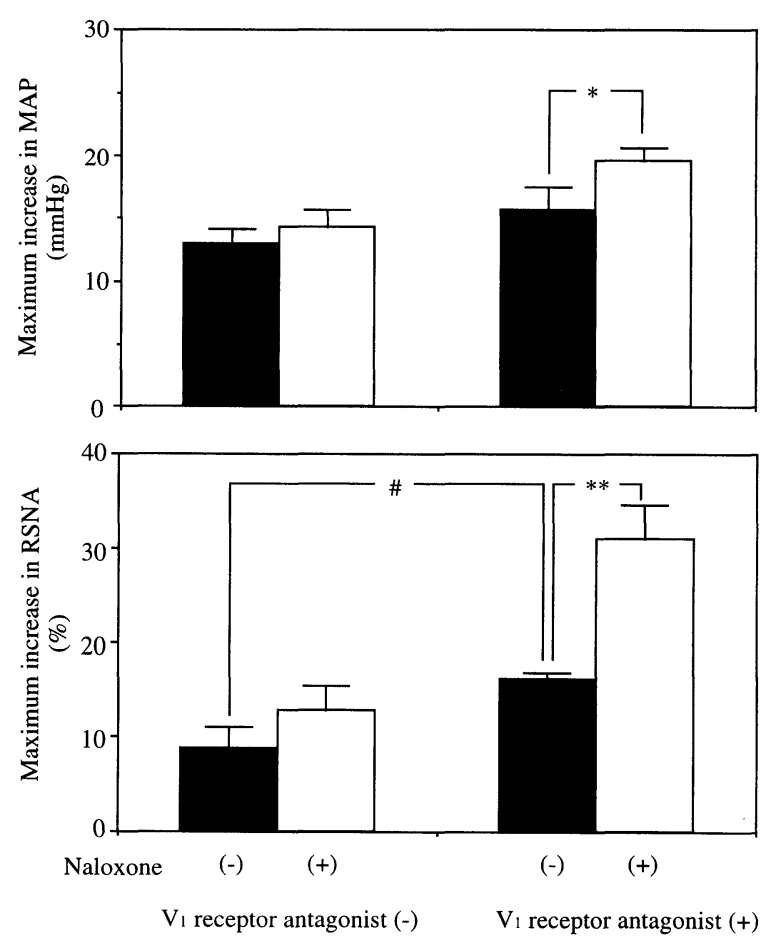

Fig. 4. Bar graph showing the maximum increases in mean arterial pressure (MAP) and renal sympathetic nerve activity (RSNA) in response to intracerebroventricular Ang II $(20 \mathrm{ng} / \mathrm{min})$ with (+) or without $(-)$ intravenous naloxone $(0.1 \mathrm{mg} / \mathrm{kg})$ pretreatment, and with $(+)$ and without $(-)$ intravenous vasopressin $V_{I}$-receptor antagonist $(30$ $\mu \mathrm{g} / \mathrm{kg})$. Values are means $\pm S E . \quad * \mathrm{p}<0.05, * * \mathrm{p}<0.01$; comparison of pretreatment with naloxone vs. vehicle in vasopressin $V_{1}$-receptor antagonized animals. $\# \mathrm{p}<0.05$; comparison of pretreatment with $V_{1}$-receptor antagonist vs. vehicle.

(5), who demonstrated that vertebral artery infusion of Ang II caused an increase in blood pressure in association with a decrease in RSNA in conscious rabbits. A number of mechanisms can account for those observations. Central Ang II causes the secretion of AVP and attenuates the baroreceptor reflex (1). Furthermore, central AVP suppresses RSNA with and without participation of baroreceptor reflexes (21), and Caine et al. (22) reported that Ang II could offset the cardioinhibitory effects of AVP. Thus, the blunted response of RSNA to ICV Ang II might be attributable to baroreceptor mediated and unmediated suppression by AVP. In fact, pretreatment with $\mathrm{V}_{1}$-receptor antagonist augmented the response of RSNA to ICV Ang II, suggesting that secreted AVP selectively interfered with the Ang II-mediated change in RSNA.

A limitation of the present study is that we could not determine the exact site where naloxone or $\mathrm{V}_{1}$ receptor antagonist acted to modulate the responses of central Ang II. However, several lines of evidence suggest that endogenous and exogenous opioid peptides act at the central nervous system to regulate blood pressure and sympathetic outflow, 
with some interactions with the renin-angiotensin system and $\operatorname{AVP}(6,9,11,23)$. Chronic naloxone infusion suppresses the plasma renin activity (24) and attenuates the development of hypertension in two-kidney one-clip Goldblatt rats (9). Furthermore, ICV injection of morphine causes an increase in AVP (25), and AVP release is inhibited by endogenous opioids during acute hemorrhagic hypotension (11). Previous studies from our laboratory and others have demonstrated that endogenous opioid peptides intrinsically suppress the sympathoadrenal outflow $(12,26)$. Moreover, endogenous and exogenous opioid peptides modulate baroreceptor reflex $(12,13)$, and intravenous naloxone acts at central $\mu$-receptors to attenuate the baroreflex control of RSNA (13). Ang II also modulates the baroreceptor reflex $(1,5,27,28)$, while AVP has been shown to augment it (29). In the present study, pretreatment with $\mathrm{V}_{1}$-receptor antagonist caused a significant increase in RSNA in response to ICV Ang II; furthermore, combined pretreatment with naloxone and $\mathrm{V}_{1}$-receptor antagonist elicited further increases in blood pressure and RSNA in response to ICV infusion of Ang II. It is difficult to determine the exact mechanisms involved in this outcome. However, the modulation of baroreceptor reflex by opioid peptides, AVP, and Ang II might account for the results of the present study. Probably both naloxone and $\mathrm{V}_{1}$-receptor antagonist dually blunted the baroreceptor reflex, and responses of blood pressure and RSNA to ICV Ang II might have been potentiated. Further studies are required to determine the combined effects of naloxone and $\mathrm{V}_{1}$-receptor antagonist on the baroreceptor reflex as well as which sites (central or peripheral) were involved in this interaction.

The dose of Ang II used in the present study (20 $\mathrm{ng} / \mathrm{min}$ ) was relatively large. Ang II infused intracerebroventricularly might leak into the systemic circulation. However, the contribution of Ang II leaking into the systemic circulation to the cardiovascular responses seemed to be minimal, because, first, ICV Ang II (20 ng/min) for $60 \mathrm{~min}$ did not cause a significant increase in plasma concentration of Ang II and second, ICV Ang II elicited a dose-related increase in MAP (Fig. 1). These two observations strongly suggest that a major part of cardiovascular and sympathetic responses induced by ICV Ang II were attributed to the central action of Ang II.

In conclusion, ICV infusion of Ang II increased MAP, plasma epinephrine, and AVP levels, with no significant change in RSNA in conscious rabbits. Synergism between naloxone and vasopressin $\mathrm{V}_{1}$-receptor antagonist unmasked the sympathetic response to ICV Ang II, leading to greater increases in blood pressure and RSNA. Modulation of the baroreceptor reflex might play an important role in interactions among Ang II, opioid peptides, and AVP, although the crucial mechanism remains unknown.

\section{Acknowledgements}

We thank Dr. K. Bridget Brosnihan, Hypertension Center, the Bowman Gray School of Medicine of Wake Forest University, for the critical reading of the manuscript.

\section{References}

1. Ferrario CM, Ueno Y, Diz DI, Barnes KL: The renin-angiotensin system: physiological actions on the central nervous system, in Zanchetti A, Tarazi RC (eds): Handbook of hypertension. Pathophysiology of hypertension - regulatory mechanisms. Vol. 8, New York, Elsevier, 1986, pp 431-454.

2. Reid IA: Interactions between ANG II, sympathetic nervous system, and baroreceptor reflexes in regulation of blood pressure. Am J Physiol 1992; 262: E763-E778.

3. Unger $\mathrm{T}$, Rascher $\mathrm{W}$, Schuster $\mathrm{C}$, et al: Central blood pressure effects of substance $\mathrm{P}$ and angiotensin II: role of the sympathetic nervous system and vasopressin. Eur J Pharmacol 1981; 71: 33-42.

4. Fukiyama K: Central action of angiotensin and hypertension - increased central vasomotor outflow by angiotensin. Jpn Circ J 1972; 36: 599-602.

5. Matsumura Y, Hasser EM, Bishop VS: Central effect of angiotensin II on baroreflex regulation in conscious rabbits. Am J Physiol 1989; 256: R694-R700.

6. Holaday JW: Cardiovascular effects of endogenous opiate system. Annu Rev Pharmacol Toxicol 1983; 23: 541-594.

7. Pfeiffer A, Feuerstein G, Zerbe RL, Faden AI, Kopin IJ: $\mu$-Receptors mediate opioid cardiovascular effects at anterior hypothalamic sites through sympathoadrenomedullary and parasympathetic pathways. Endocrinology 1983; 113: 929-938.

8. Quock RM, Vaughn LK, Kouchich FJ: Influence of chronic naloxone treatment on development of hypertension in the spontaneously hypertensive rat. Naunyn Schmiedebergs Arch Pharmacol 1984; 325: 88-90.

9. Chen M, Lee J, Malvin RL, Huang BS: Naloxone attenuates development of hypertension in two-kidney one-clip Goldblatt rats. Am J Physiol 1988; 255: E839-E842.

10. Szilagyi JE, Ferrario CM: Central opiate system modulation of the area postrema pressor pathway. Hypertension 1981; 3: 313-317.

11. Schadt JC, Hasser EM: Interaction of vasopressin and opioids during rapid hemorrhage in conscious rabbits. Am J Physiol 1991; 260: R373-R381.

12. Matsumura K, Abe I, Fukuhara $M$, et al: Naloxone augments sympathetic outflow induced by centrally administered endothelin in conscious rabbits. Am J Physiol 1994; 266: R1403-R1410.

13. Matsumura K, Abe I, Tominaga M, Tsuchihashi T, Kobayashi K, Fujishima M: Differential modulation by $\mu^{-}$and $\delta$-opioids on baroreceptor reflex in conscious rabbits. Hypertension 1992; 19: 648-652.

14. Matsumura K, Abe I, Tsuchihashi T, Tominaga M, Kobayashi K, Fujishima M: Central effect of endothelin on neurohormonal responses in conscious rabbits. Hypertension 1991; 17: 1192-1196.

15. Yoshimura M, Komori T, Nakanishi T, Takahashi H: Estimation of sulphoconjugated catecholamine concentrations in plasma by high-performance liquid chromatography. Ann Clin Biochem 1993; 30: 135141. 
16. Nohta H, Mitsui A, Ohkura Y: Spectrofluorimetric determination of catecholamines with 1,2-diphenylethylenediamine. Anal Chim Acta 1984; 165: 171176.

17. Iwaeda T, Kuroki M, Ohta K, Ishimura S, Takahashi $\mathrm{H}$, Watanabe $\mathrm{H}$ : Development of fully automated catecholamine analyzer, HLC-8030. J Tosoh Res 1988; 32: 59-64.

18. Ishikawa N, Kallman $\mathrm{CH}$, Sagawa K: Rabbit carotid sinus reflex under pentobarbital, urethan, and chloralose anesthesia. Am J Physiol 1984; 246: H696H701.

19. Matsukawa K, Ninomiya I: Anesthetic effects on tonic and reflex renal sympathetic nerve activity in awake cats. Am J Physiol 1989; 256: R371-R378.

20. Matsumura K, Abe I, Tsuchihashi T, Fujishima M: Central nitric oxide attenuates the baroreceptor reflex in conscious rabbits. Am J Physiol 1998; 274: R1142-R1149.

21. Suzuki S, Takeshita A, Imaizumi $\mathrm{T}$, et al: Central nervous system mechanisms involved in inhibition of renal sympathetic nerve activity induced by arginine vasopressin. Circ Res 1989; 65: 1390-1399.

22. Caine AC, Lumbers ER, Reid IA: The effects and interactions of angiotensin and vasopressin on the heart of unanaesthetized sheep. J Physiol 1985; 367:
$1-11$.

23. Szilagyi JE: Endogenous opiate modulation of baroreflexes in normotensive and hypertensive rats. Am J Physiol 1988; 255: H987-H991.

24. Szilagyi JE, Ferrario CM: Cardiovascular effects of chronic naloxone infusion in normal dogs. Neuroendocrinology 1986; 43: 110-114.

25. Aziz LA, Forsling ML, Woolf CJ: The effect of intracerebroventricular injections of morphine on vasopressin release in the rat. $J$ Physiol 1981; 311: 401-409.

26. Bouloux PMG, Newbould E, Causon R, et al: Differential effect of high-dose naloxone on the plasma adrenaline response to the cold-pressor test. Clin $\mathrm{Sci}$ 1989; 76: 625-630.

27. Guo GB, Abboud FM: Angiotensin II attenuates baroreflex control of heart rate and sympathetic activity. Am J Physiol 1984; 246: H80-H89.

28. Hayashi J, Takeda K, Kawasaki S, et al: Central attenuation of baroreflex by angiotensin II in normotensive and spontaneously hypertensive rats. Am J Hypertens 1988; 1: 15S-22S.

29. Cowley AW Jr, Merrill D, Osborn J, Barber BJ: Influence of vasopressin and angiotensin on baroreflexes in the dog. Circ Res 1984; 54: 163-172. 